\title{
The effect of low molecular weight surfactants and proteins on surface stickiness of sucrose during powder formation through spray drying
}

\author{
B. Adhikari ${ }^{\mathrm{a}, *}$, T. Howes ${ }^{\mathrm{b}}$, B.J. Wood ${ }^{\mathrm{c}}$, B.R. Bhandari ${ }^{\mathrm{d}}$ \\ ${ }^{a}$ School of Science and Engineering, The University of Ballarat, Mount Helen, VIC 3353, Australia \\ ${ }^{\mathrm{b}}$ School of Engineering, The University of Queensland, QLD 4072, Australia \\ ' School of Molecular and Microbial Sciences, The University of Queensland, QLD 4072, Australia \\ ${ }^{\mathrm{d}}$ School of Land and Food Sciences, The University of Queensland, QLD 4072, Australia
}

\section{A R T I C L E I N F O}

\section{Article history:}

Received 17 March 2008

Received in revised form 23 December 2008

Accepted 9 January 2009

\section{Keywords:}

Stickiness

Sugar-rich foods

Protein

Low molecular weight surfactants

Spray drying

\section{Introduction}

The use of spray drying to produce powders from formulations containing low molecular weight sugars is limited because of their inherent stickiness. This stickiness results in depositions on the dryer wall, roof, conical section and conveying ducts (Bhandari et al., 1997a; Langrish, 2007). In the case of honey, which is a typ ical sugar rich material, it is not yet possible to convert it into a powder without the addition of a significant amount of high molecular weight carrier material such as maltodextrin. The sticky food powders which are recovered are highly hygroscopic and tend to easily cake or lump and are very difficult to store. They require packaging with very high water barrier properties. This secondary powder stickiness can be triggered due to pressure and tempera

\footnotetext{
* Corresponding author. Tel.: +61 3 53279249; fax: +61 353279240

E-mail address: b.adhikari@ballarat.edu.au (B. Adhikari).
}

ture changes or cycling during storage and transportation (Adhik ari et al., 2001).

The inherent sticky behaviour of sugar and acid rich foods re quires special processing and material centric intervention to allow economically viable production. Process modifications include the use of low temperature and low humidity air, wall cooling or the introduction of cold air to the bottom of the dryer. Frequent mechanical sweeping is another modification. Material modifica tions at present include the addition of drying carriers such as maltodextrins, gums and high molecular food hydrocolloids.

The efficacy of low dextrose equivalent (DE) maltodextrins, as drying aids, is due to their rapid film or shell forming property and the relatively low moisture diffusivity of these films (Adhikari et al., 2003). The earlier the film is formed in the drying process, the better will be the maltodextrin's efficacy as a drying aid. In this context, it has also been found that proteins such as whey protein isolates (WPI) and sodium caseinates form smooth and non sticky films or shells much earlier than the maltodextrins and that the 
recovery of powders is much higher when a small amount of pro teins are added to the solution being spray dried (Adhikari et al., 2007a). This is an indication that proteins can act as a very effective drying aid. This argument can also be supported by the much low er droplet to probe tensile pressure of lactose WPI mixture solu tions compared to that of the sugar solutions (Adhikari et al., 2007b).

In pharmaceutical science, the competitive adsorption of pro teins and LMS has been extensively researched. The application of the LMS in therapeutic drugs is required to limit or prevent the exposure of active protein ingredients to the air water inter face (Maa and Hsu, 1997; Maa et al., 1998). Since both proteins and LMS provide enhanced emulsion stability, a series of studies were undertaken to understand the mechanisms by which the LMS displace proteins at air water and fat water interfaces (Wil liams and Prins, 1996; Dickinson, 1999; Mackie et al., 1999, 2000; Gunning et al., 2004; Williams and Prins, 1996; Rouimi et al., 2005).

Experiments conducted in our laboratories have shown that the preferential migration of proteins driven by their surface activity allows the generation of highly surface engineered powders of su gar and acid rich foods. In a pilot scale spray dryer, the use of so dium caseinate and WPI led to the excellent recovery of $85 \% 90 \%$ of amorphous sucrose powder when a mere $0.125 \%$ of these pro teins are introduced in the solution (Adhikari et al., in press). This compared with the $>16 \%$ of maltodextrin (DE6) required to obtain the same extent of recovery of the sucrose powder under similar drying conditions (Truong et al., 2005).

It is known that LMS compete with protein for the air water interface (Pugnaloni et al., 2004; van Aken, 2003; Rouimi et al., 2005; Mackie et al., 2000). With a smaller size they are advantaged kinetically to occupy the surface as proteins have relatively lower diffusivities (van Aken, 2003). It is of practical significance to inves tigate the implication of the presence of trace amount of LMS along with proteins in the surface stickiness of sugar rich foods. This is because it has been observed that there is a presence of trace amount of LMS in industrially obtained sugar samples (Adhikari et al., 2007b).

Hence the aim this project was to investigate the competitive migration of protein and LMS to the surface of powders of a model sugar. The project also studied the implication of this competitive migration to the stickiness through the recovery of those powders in pilot scale spray drying.

\section{Materials and methods}

\subsection{Materials}

Sucrose with 99.5\% purity (Sigma Aldrich, Australia) was used as model sugar rich food. A reagent grade Sodium dodecyl Sulfate (Na DS) with $98.5 \%$ purity and Polysorbate 80 (Tween $80,10 \%$ solution) from Sigma Aldrich, Australia were used as received. So dium caseinate (ALATAL ${ }^{\text {TM }} 180$ ) and hydrolyzed whey protein iso late (ALATAL ${ }^{\mathrm{TM}}$ 817) were obtained, courtesy of NZMP, New Zealand and used as received.

\subsection{Methods}

\subsubsection{Solution preparation}

The protein sugar solution was prepared by heating up the solution to $50{ }^{\circ} \mathrm{C}$ and agitating with the aid of a magnetic stirrer. The protein was first dissolved by adding small amounts of the pre weighed sample at a time under constant stirring to avoid clumping of the powders. The stirring was mild in order to avoid air entrainment. Once the protein was dissolved, sucrose was added. The sucrose to protein solid ratio was maintained at 99.5:0.5 and 99.0:1.0 on dry solids basis. The total solids fraction in the feed solution was fixed at $25 \%$ by weight. Thus, the nominal feed concentration of the protein in the solution was either $0.25 \%$ or $0.125 \%$. One kilogram solution bathes were prepared. The inher ent moisture content in the protein samples was determined and compensated for. The moisture content of the crystalline sucrose was taken to be zero. The solution matrix is presented in Table 1. The protein sugar LMS solutions were prepared by adding $0.05 \%$ (nominal feed concentration) Na DS or Tween 80 to the solution under sufficient stirring. Solutions were prepared with $250 \mathrm{~mL}$ water along with the protein and surfactant, if any, first on a hot plate maintained at $45^{\circ} \mathrm{C}$, to ensure that all solids will successfully dissolved, before adding the sucrose and the remaining water. All the moisture contents, reported in the ensuing sections are on a weight/weight basis.

\subsubsection{Moisture determination}

The moisture content of the powder was determined through vacuum drying (Thermoline Scientific, Australia) at $70^{\circ} \mathrm{C}$ and 500 mbar for $24 \mathrm{~h}$ followed by cooling the samples to the room temperature in desiccators in the presence of an excess amount of silica gel. Duplicate or triplicate tests were carried out.

\subsubsection{Powder production}

Powder from both the protein sugar and protein sugar LMS solutions were produced using a pilot scale spray dryer (SL20, Sau rin Company, Victoria, Australia) with a water evaporating capacity of $2 \mathrm{~kg} / \mathrm{hr}$. The inlet and outlet temperatures were maintained at $170^{\circ} \mathrm{C}$ and $70^{\circ} \mathrm{C}$, respectively. The powders were collected from the cyclone, and in the case of sweeps, they were collected by lightly sweeping the inner dryer wall.

\subsubsection{Water activity}

Water activity of the powder samples was determined using AquaLab 3TE Series (Decagon, USA) water activity meter. The tem perature was maintained at $25 \pm 0.5^{\circ} \mathrm{C}$ during the tests. Duplicate or triplicate tests were carried out.

\subsection{5. $X$ ray photoelectron spectroscopy}

$\mathrm{X}$ ray photoelectron spectroscopy (XPS) or electron spectros copy for chemical analysis (ESCA) is a well established method em ployed for direct measurement of surface elemental composition of food powders (Faldt and Bergenstahl, 1996; Kim et al., 2003). A de tailed description of the use of ESCA as a method to measure the surface composition of dairy based food powders can be obtained from various sources (Faldt et al., 1993; Kim et al., 2002; Nijdam and Langrish, 2006).

Firstly, ESCA measurements for sucrose, sodium caseinate, WPI, Na DS and Tween 80 were carried out to determine the surface composition of these materials. It is assumed that the surface ele mental composition of pure materials is the same as its bulk ele mental composition. Subsequently, the surface elemental composition of all the spray dried powders was determined. Prior to subjecting to the ESCA test, the samples were outgassed for $72 \mathrm{~h}$. The ESCA was performed on a Kratos AXIS Ultra with a $150 \mathrm{~W}$ monochromatic A1 X ray source. Each analysis started with a sur vey scan from 0 to $1200 \mathrm{eV}$ with a residence time of $100 \mathrm{~ms}$, pass energy of $160 \mathrm{eV}$ at steps of $1 \mathrm{eV}$, with a 1 sweep. For the high res olution analysis, the number of sweeps was increased, the pass en ergy was lowered to $20 \mathrm{eV}$, at steps of $50 \mathrm{meV}$ and the residence time was increased to $250 \mathrm{~ms}$. Data were acquired using a Kratos Axis ULTRA X ray spectrometer, incorporating a $165 \mathrm{~mm}$ hemi spherical electron energy analyzer. The incident radiation was Monochromatic A1 X rays $(1486.6 \mathrm{eV})$ at $225 \mathrm{~W}(15 \mathrm{kV}, 15 \mathrm{~mA})$. Survey (wide) scans were at analyzer pass energy of $160 \mathrm{eV}$. Base 
Table 1

Formulation matrix for solution preparation.

\begin{tabular}{|c|c|c|c|c|}
\hline & WPI (g) & Sodium caseinate $(\mathrm{g})$ & Sucrose $(\mathrm{g})$ & Water $(\mathrm{g})$ \\
\hline $0.125 \%$ sodium caseinate & 0 & 1.33 & 248.75 & 750 \\
\hline $0.25 \%$ sodium caseinate & 0 & 2.66 & 247.5 & 750 \\
\hline $0.125 \%$ WPI & 1.34 & 0 & 248.75 & 750 \\
\hline $0.25 \%$ WPI & 2.68 & 0 & 247.5 & 750 \\
\hline
\end{tabular}

pressure in the analyser chamber was $10{ }^{9}$ Torr and during sample analyses it was maintained at $10^{8}$ Torr.

ESCA was applied to measure the relative atomic concentration of carbon, nitrogen, oxygen, sulphur and sodium in the samples. The elemental composition of sucrose, sodium caseinate and $\mathrm{Na}$ DS obtained from ESCA were compared with its theoretical compo sition. A numerical method based on matrix inversion is available to determine the surface coverage of individual components based on the ESCA data (Faldt et al.,1993; Kim et al., 2002; Shrestha et al., 2007). However, as nitrogen is not present in sucrose and the LMS compositions, the protein surface coverage could be calculated from a simple nitrogen balance.

\subsubsection{Surface tension, interfacial viscosity and viscoelasticity}

All surface properties (surface tension and viscoelasticity) of the solutions were measured with the Sinterface PAT 1 (Sinterface Technologies, Germany). Two different modes of tests, i.e., bub ble in droplet and droplet in air were used. Sucrose and sodium caseinate formed clear solutions; hence, the bubble in droplet method was used. Solutions containing WPI formed opaque or murky solutions and hence the droplet in air method was used. For the former method, distilled water was poured into the cuvette, and the settings of the tensiometer were adjusted to ensure that the surface tension of water remained within the range of 72.5 $73.0 \mathrm{mN} / \mathrm{m}$. Subsequently, air was pumped into the water to gen erate a small bubble. The camera was then adjusted to focus on the droplet. Once these adjustments were made, the water was poured out and the cuvette was dried. Subsequently, the test solu tion was poured in. $8 \mathrm{~mm}^{3}$ of solution was used for each run. Bub bles with $30 \mathrm{~mm}^{2}$ surface area were generated and surface tension values were noted. After the surface tension measurement, an area oscillation function, usually $1921 \mathrm{~mm}^{2}$ was used. The oscillation protocol was holding (10 s) oscillation (60s) holding (10 s) in se quence. Surface tension values were measured at 30 and $45 \mathrm{~min}$ by best fitting bubble shapes with the Young Laplace equation. The Fourier Transform was applied to the area oscillation function in order to obtain the dilatational data. The cuvette was cleaned and dried before commencing the next run.

For the droplet in air, a pendant method was used. Distilled water (MilliQ) was used to clean the tubes and the syringe fol lowed by compressed air to dry the passage. The solution was pumped for a few minutes to purge the passage. A droplet with a surface area of $30 \mathrm{~mm}^{2}(15.45 \mu \mathrm{L})$ was generated at the tip of the needle. The remainder of the experiment procedure was of the same as the bubble in droplet process. The passage was cleaned and dried using water and compressed air before commencing the next run. Surface property data presented in this paper were obtained between 30 and 45 min after bubbles and droplets were created.

\section{Results and discussions}

\subsection{Powder recovery of sugar protein system}

The powders of sucrose Na C and sucrose WPI with and with out LMS were collected from spray drying trials. Powders were recovered from cyclone and the bottom of the dryer (sweep) by lightly sweeping. The recovery was calculated as the ratio of the mass of solids collected to the solid mass in feed solution. Table 2 provides the recovery of these powders. Similarly, Figs. 1 and 2 show the recovery of sucrose Na C and sucrose WPI, separately.

The equilibrium relative humidity (described as a water activ ity, $a_{\mathrm{w}}$ ) and moisture content of the powders were measured immediately after collection. An adequate time was provided to bring the powder temperature down to room temperature. The powders were immediately sealed in the measuring cap to stop changes in moisture. The moisture content and $a_{\mathrm{w}}$ values are pre sented in Table 3. It can be seen from this table that the highest moisture content and $a_{\mathrm{w}}$ are $2.6 \%$ and 0.24 , respectively. Further more, the majority of water activity values are below 0.2 . These values fall within commonly observed moisture and $a_{\mathrm{w}}$ values in industrial spray drying.

Table 2 and Figs. 1 and 2 show that the total recovery of sucrose without addition of protein is about $18 \%$ and that no powder was recovered from the cyclone. The powders recovered from the sweep were also fully crystalline. This may be due to the fact that the semi dried sucrose wall deposits crystallized during the cool ing stage of the process following spraying. As these powders were not any closer to normal spray dried powders, the recovery, in es sence, can be taken as zero. Hence, the entire sucrose solids in the feed were lost as wall deposits. This result agrees with previous observations that no powders were recovered from spray drying trials of sucrose in similar drying conditions (Truong et al., 2005). When $0.5 \%$ of sucrose solid was replaced with Na C (Fig. 1) and WPI (Fig. 2 ) the total recovery rose to $84.7 \%$ and $84.1 \%$ respectively. The cyclone recovery, which is an in indicator of spray drying suc cess (Bhandari et al., 1997), increased to $60.8 \%$ and $53.4 \%$, respec tively. As greater than $50 \%$ recovery in the cyclone has been considered to be a successful drying (Bhandari et al., 1997), the addition of addition of $0.125 \%$ protein in the feed made it possible to spray dry sucrose solutions, which otherwise was not possible. When the $1 \%$ of sucrose solid was replaced by Na C and WPI, the total powder recovery remained at close to $85 \%$.

Proteins preferentially migrate to the air water interface of su gar solutions and form a protein rich film there. When this film is subjected to hot and dry air, it is converted into a glassy skin which grows in thickness as the drying progresses. This skin was found to withstand greater than $10 \mathrm{kPa}$ of compressive pressure (Adhikari et al., 2007a). Hence, the greatly enhanced powder recovery with addition of $0.125 \%$ of protein in solution indicates that this film is successful in overcoming the coalescence of droplets as well as sticky interactions of the droplets or particles at the wall. As will be discussed later, the nature of the films and the dilational elastic ity of these two proteins are quite different. However, this differ ence does not appear to influence their ability to overcome the droplet droplet coalescence and particle wall stickiness which are two key factors that cause stickiness. These results show that protein concentration greater than $0.125 \%$ does not bring about higher powder recovery. In fact, when losses due to fines are con sidered, this amount of protein addition appears to completely ne gate the loss due to stickiness by overcoming the sticky behaviour of sucrose solutions. Hence, when spray during of highly sticky su gar rich solution is concerned, protein can act as very effective dry ing aids. 
Table 2

Recovery of sucrose-sodium caseinate and sucrose-WPI powders with or without surfactants (Na-DS and Tween-80).

\begin{tabular}{|c|c|c|c|}
\hline \multirow[t]{2}{*}{ Sample } & \multicolumn{3}{|c|}{ Powder Recovery (\%) } \\
\hline & Cyclone & Sweep & Total \\
\hline Sucrose & $0.00 \pm 0.00$ & $18.10 \pm 0.72$ & $18.10 \pm 0.72$ \\
\hline Sucrose:Na-C (99.0:1.0) w/o surfactant & $69.25 \pm 0.6$ & $16.01 \pm 0.72$ & $85.26 \pm 0.12$ \\
\hline Sucrose: Na-C $(99.0: 1.0)$ with Na-DS & $38.31 \pm 0.43$ & $30.06 \pm 0.63$ & $68.37 \pm 1.06$ \\
\hline Sucrose:Na-C (99.0:1.0) with Tween-80 & $0.00 \pm 0.00$ & $0.00 \pm 0.00$ & $0.00 \pm 0.00$ \\
\hline Sucrose:Na-C (99.5:0.5) w/o surfactant & $60.08 \pm 1.94$ & $24.62 \pm 0.38$ & $84.70 \pm 1.43$ \\
\hline Sucrose:Na-C (99.5:0.5) with Na-DS & $33.25 \pm 0.57$ & $30.69 \pm 0.05$ & $63.93 \pm 0.52$ \\
\hline Surose:Na-C (99.5:0.5) with Tween-80 & $0.00 \pm 0.00$ & $0.00 \pm 0.00$ & $0.00 \pm 0.00$ \\
\hline Sucrose:WPI (99.0:1.0) w/o surfactant & $60.1 \pm 0.7$ & $25.07 \pm 0.61$ & $85.17 \pm 1.31$ \\
\hline Sucrose:WPI (99.0:1.0) with Na-DS & $36.51 \pm 0.24$ & $27.35 \pm 0.13$ & $63.86 \pm 0.11$ \\
\hline Sucrose: WPI (99.0:1.0) with Tween-80 & $0 \pm 0.00$ & $0 \pm 0.00$ & $0 \pm 0.00$ \\
\hline Surose:WPI (99.5:0.5) w/o surfactant & $53.41 \pm 0.94$ & $30.69 \pm 0.94$ & $84.1 \pm 1.88$ \\
\hline Sucrose:WPI (99.5:0.5) with Na-DS & $16.84 \pm 0.04$ & $21.8 \pm 1.4$ & $38.64 \pm 1.36$ \\
\hline Sucrose:WPI (99.5:0.5) with Tween-80 & $0 \pm 0.00$ & $0 \pm 0.00$ & $0 \pm 0.00$ \\
\hline
\end{tabular}

\subsection{Powder recovery of sugar protein surfactant system}

To understand the implication of different LMS on sucrose solu tion stickiness, both non ionic and ionic surfactants were tested. Polysorbate 80 (Tween 80 ) is a non ionic surfactant whereas so dium dodecyl phosphate (Na DS) is an ionic one. Table 2 presents the recovery from sugar protein solutions when trace amount of surfactants were added to the solution. Fig. 1 presents the effect of these surfactants on recovery of sugar $\mathrm{Na} C$ solution while Fig. 2 presents the effect of the surfactants on the sucrose WPI solution.

As can be seen from this table and the figures, when merely $0.05 \%$ of Tween 80 was added to both the sucrose Na C and su crose WPI solutions, no powders were recovered. The entire inner surface of the dryer was covered with a thick deposition of thermo plastic solid. The presence of a higher amount of proteins $(0.25 \%)$ or the use of different types of protein made no difference.

The effect of $\mathrm{Na}$ DS was somewhat different. When $0.05 \%$ of $\mathrm{Na}$ DS was added to sucrose $\mathrm{Na} C(99.5: 0.5)$ solution the powder recovery was $64 \%$ which is down by $21 \%$ compared to the recovery from the same solution in the absence of Na DS. It is of interest that the cyclone recovery was reduced to by half while the sweep recovery increased by 7\%. Similarly, when the same amount of $\mathrm{Na}$ DS was added to sucrose WPI (99.5:0.5) solution, 39\% recovery was measured and both cyclone and sweep recovery were greatly re duced. When a higher amount of protein was present (sucrose: Na $C=$ sucrose:WPI $=99: 1$ ), the total recovery increased slightly to $68 \%$ in the case of sucrose $\mathrm{Na}$ C. However it increased substan tially to $63 \%$ in the case of sucrose WPI. We can conclude that, where the powder recovery is concerned, the effect of Na DS on the effectiveness of these two proteins is almost identical when they were present at concentrations greater than $0.25 \%$ in the solu tion, whereas at lower concentrations $(0.125 \%)$ WPI gave much re duced effectiveness in reducing the effects of stickiness on recovery.

\subsection{Mechanism of surfactant protein interaction in sugar matrix}

The fundamentally different effects of Tween 80 and Na DS in the powder recovery observed in this study can best be explained through the molecular interaction of surfactants and proteins in sugar solutions. To be able to understand the molecular level inter actions, parameters such as surface activity, dilational surface

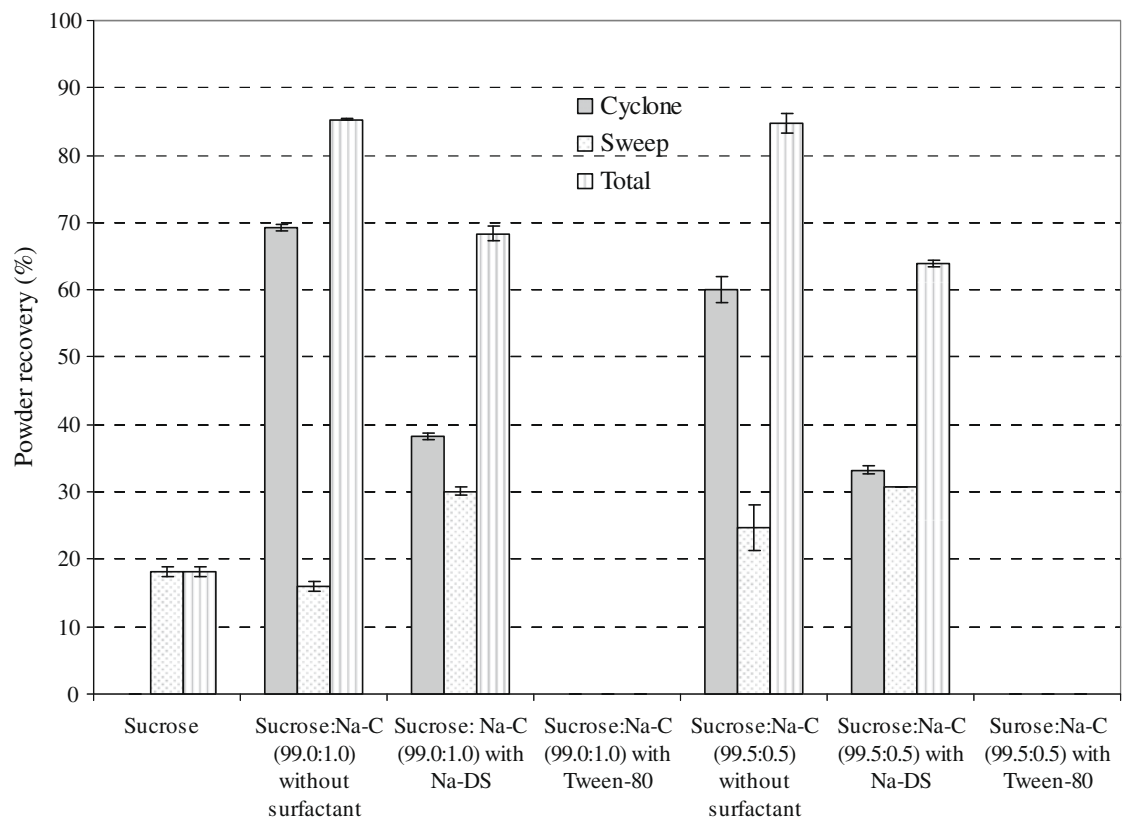

Fig. 1. Powder recovery of sucrose-sodium caseinate composite powders with and without Na-DS and Tween-80 addition. 


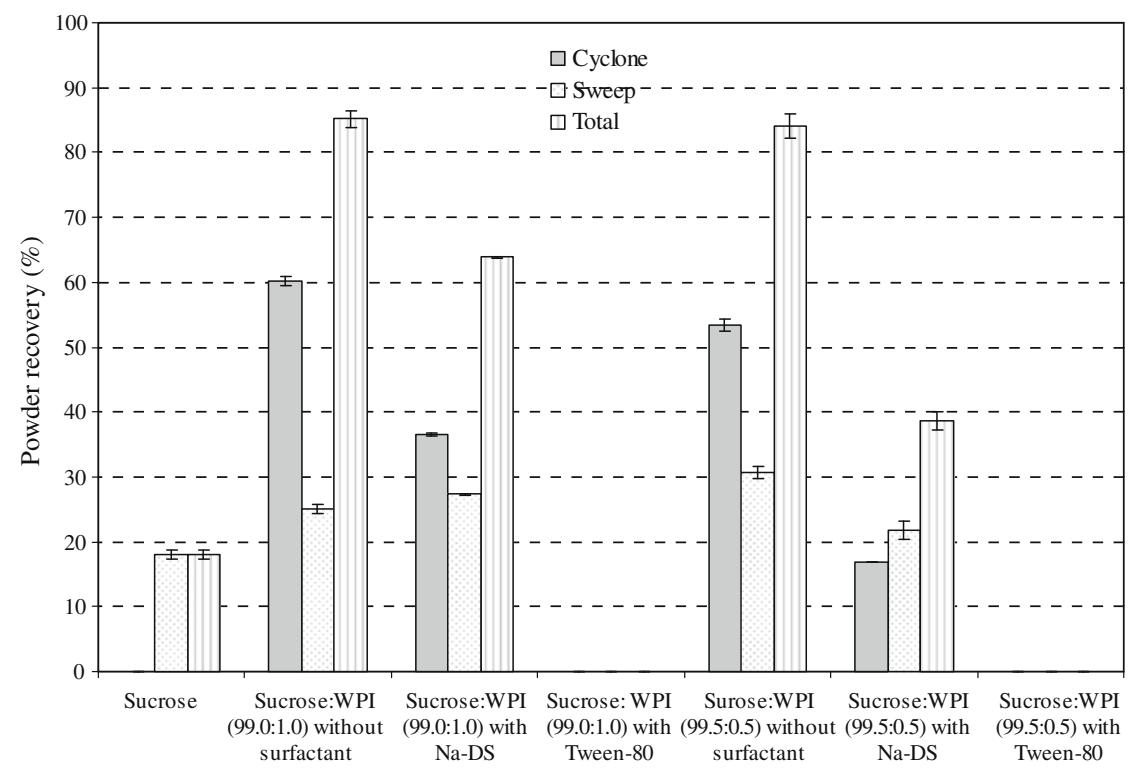

Fig. 2. Powder recovery of sucrose-WPI composite powders with and without Na-DS and Tween-80 addition.

properties and surface composition of the solutions/powders have to be experimentally determined.

\subsubsection{Surface activity of sugar protein, and sugar protein surfactant solutions}

The surface tension and surface pressure values of sucrose $\mathrm{Na}$ $\mathrm{C}$ and sucrose WPI solutions with and without the LMS are pre sented in Figs. 3 and 4, respectively. Surface tension values of su crose, Na C and WPI solutions are given as reference.

It can be seen from these figures that the surface tension value of $25 \%$ sucrose solution is $73.9 \mathrm{mN} / \mathrm{m}$, which is close to the litera ture value (Weast, 1988). The surface tension values of both $\mathrm{Na} C$ and WPI in the concentration range of $0.125 \%$ and $0.25 \%$ are in the range of $4045 \mathrm{mN} / \mathrm{m}$. This is within the equilibrium surface ten sion values reported in literature (Adhikari et al., 2007a), which indicates that the proteins have had sufficient time to migrate to the surface. Furthermore, the surface tension values of the su crose Na C and sucrose WPI solutions in the absence of LMS are close to the surface tension values of the corresponding protein concentrations without sucrose. This also suggests that the sucrose solution has less effect on surface activity of the mixture solution at this level of protein concentrations.

One of the interesting observations from these figures is that the surface tension values of Tween 80 solutions are higher than the corresponding Na DS values with $\mathrm{Na} C$ as well as with WPI. This indicates that if the lowered surface tension is to directly cor relate to the surface occupation by the surfactant or the displace ment of the proteins from the surface, the Na DS should have occupied more surface and hence displaced more protein com

Table 3

Water activity values of the sucrose-protein powder with and without Na-DS.

\begin{tabular}{lll}
\hline Sample & Moisture (\%) & $a_{\mathrm{w}}$ \\
\hline Sucrose:Na-C (99.0:1.0) w/0 surfactant & $2.203 \pm 0.081$ & $0.208 \pm 0.002$ \\
Sucrose:Na-C (99.0:1.0) with Na-DS & $1.733 \pm 0.02$ & $0.201 \pm 0.006$ \\
Sucrose: Na-C (99.5:0.5) w/o surfactant & $2.762 \pm 0.027$ & $0.239 \pm 0.004$ \\
Sucrose:Na-C (99.5:0.5) with Na-DS & $2.358 \pm 0.015$ & $0.165 \pm 0.002$ \\
Sucrose:WPI (99.0:1.0) w/o surfactant & $2.051 \pm 0.011$ & $0.161 \pm 0.001$ \\
Sucrose:WPI (99.0:1.0) with Na-DS & $2.498 \pm 0.046$ & $0.156 \pm 0.00$ \\
Sucrose:WPI (99.5:0.5) w/o surfactant & $2.504 \pm 0.009$ & $0.173 \pm 0.001$ \\
Sucrose:WPI (99.5:0.5) with Na-DS & $2.616 \pm 0.017$ & $0.226 \pm 0.001$ \\
\hline
\end{tabular}

pared to the Tween 80 . This has not been substantiated through the recovery of the powders. This means that from the view point of surface activity alone, the zero recovery of powder in the pres ence of $0.05 \%$ Tween 80 cannot be explained. Hence, the kinetics of surfactant protein surface interactions must be responsible for this outcome.

It has to be pointed out here that the equilibrium surface ten sion values of sucrose protein solutions with or without the pres ence of these LMS are not very different. The equilibrium surface tension of proteins are lower than that of the Tween 80 itself. If the surface tension alone was driving force, then, the Tween 80 should be unable to dislodge and displace the proteins that have previously occupied the whole air water interface. If that had hap pened, then, addition of Tween 80 should have no effect on the powder recovery. It appears that the kinetics of the movement rather than the equilibrium surface tension plays the dominant role here. As Tween 80 has a much higher diffusivity than the pro tein, it is able to move to the surface much faster.

\subsubsection{Surface dilational elasticity of sugar protein and sugar protein} surfactant solutions

The surface dilational elasticity of the sucrose $\mathrm{Na} C$ and su crose WPI solutions with and without surfactant addition is given in Figs. 5 and 6, respectively. The dilational elasticity values for the LMS and proteins are also provided as a reference. Some interesting and relevant features can be seen here. First, it appears that the interfacial or dilational elasticity of $\mathrm{Na} \mathrm{C}$ is quite different than that of WPI. In case of $\mathrm{Na} C$ the dilational elasticity decreases as the concentration of protein increases on the surface. This means that the $\mathrm{Na} \mathrm{C}$ molecules are not rigid and form flexible and cohe sive film at the air water interface (Gunning et al., 2004). The dila tional elasticity of $0.25 \% \mathrm{Na} \mathrm{C}$ is $11.2 \pm 1.2 \mathrm{mN} / \mathrm{m}$ which agrees well with the literature value (Williams and Prins, 1996). The dila tional elasticity value of $0.05 \%$ Tween 80 also appears to be close to this value. On the other hand, Na DS has a lower value which indi cates that this surfactant is less rigid than Tween 80 . Here too, $\mathrm{Na}$ DS is able to lower the interfacial elasticity of the mixture solutions greater than Tween 80 . The interfacial elasticity of $0.25 \%$ WPI solu tion was $64.41 \pm 3.4 \mathrm{mN} / \mathrm{m}$ and that of $0.125 \%$ WPI $45.4 \pm 2.1 \mathrm{mN} /$ $\mathrm{m}$, which is much higher than the corresponding $\mathrm{Na} \mathrm{C}$ solutions. It appears that both the sucrose and surfactants are able to lower the elasticity of WPI. It is known that the $\beta$ lactoglobulin has the 


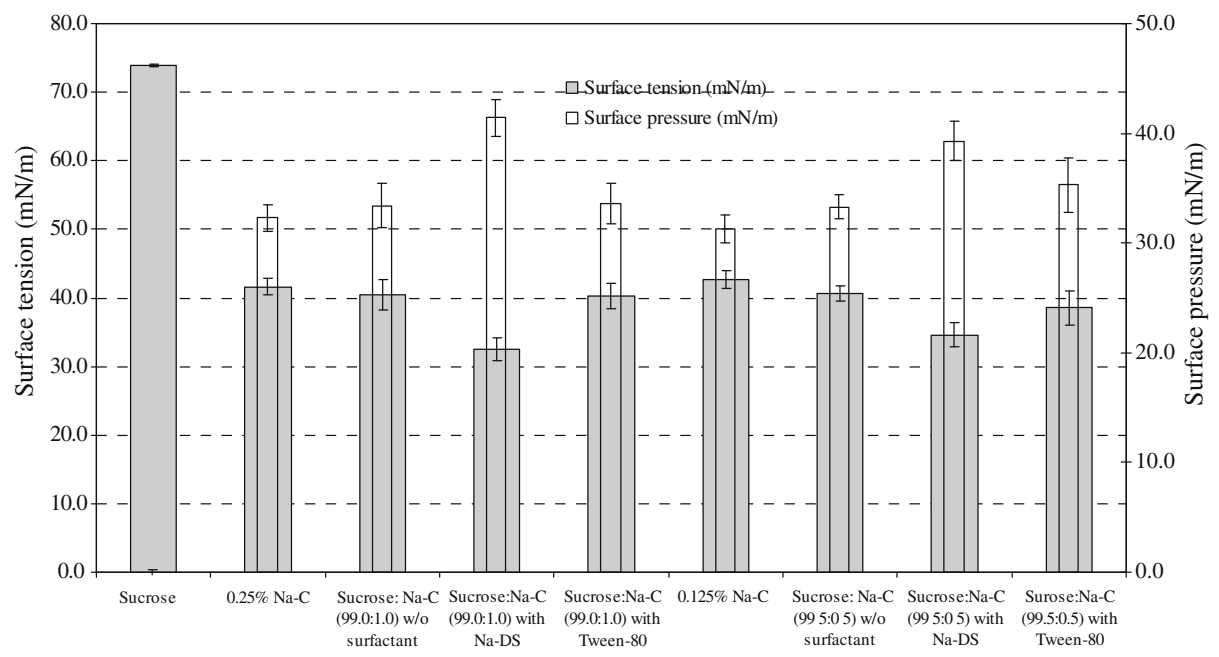

Fig. 3. Surface tension and surface pressure of sucrose-Na-C, with and without Na-DS Tween-80 addition.

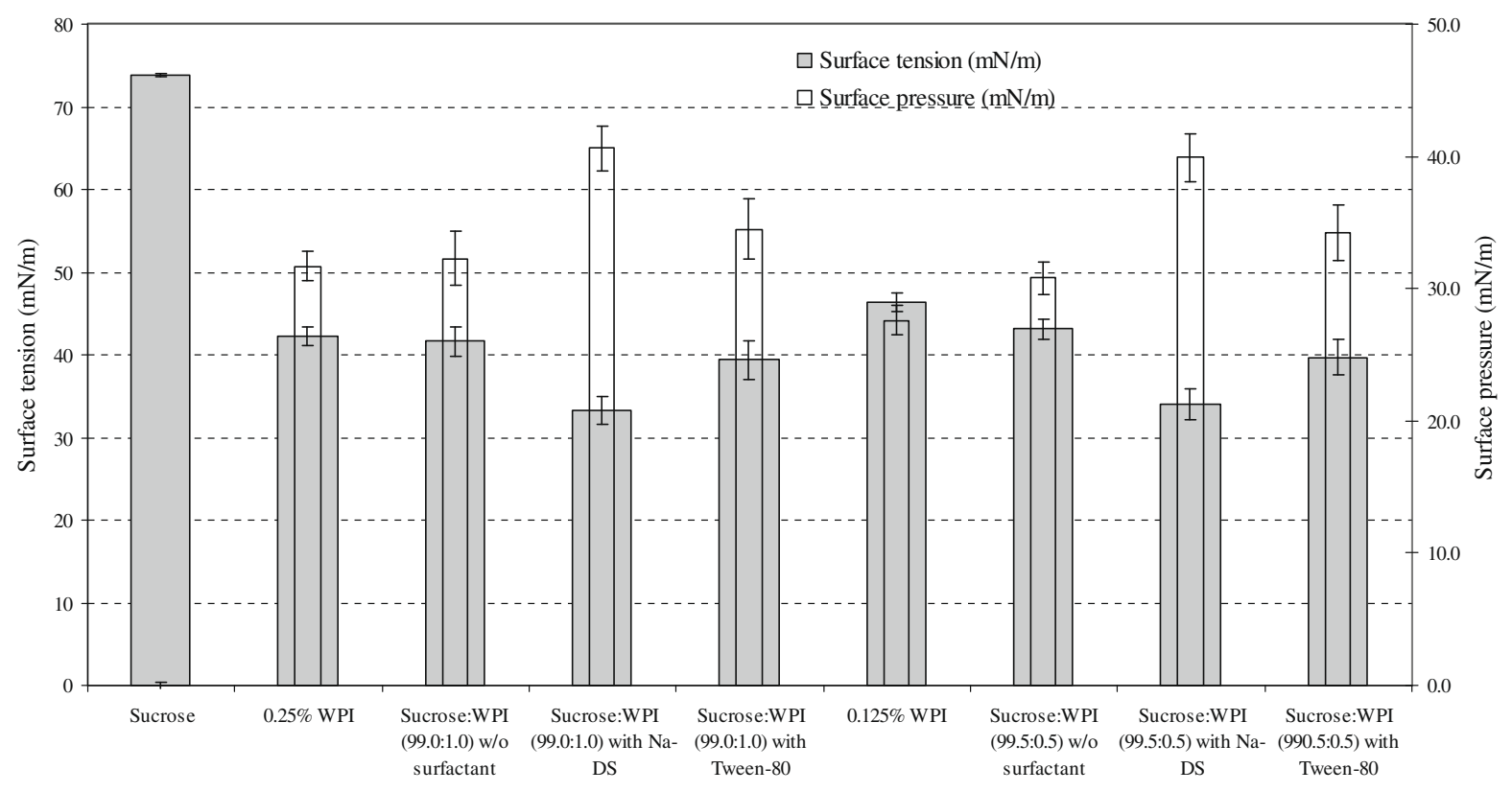

Fig. 4. Surface tension and surface pressure of sucrose-WPI, with and without Na-DS and Tween-80 addition.

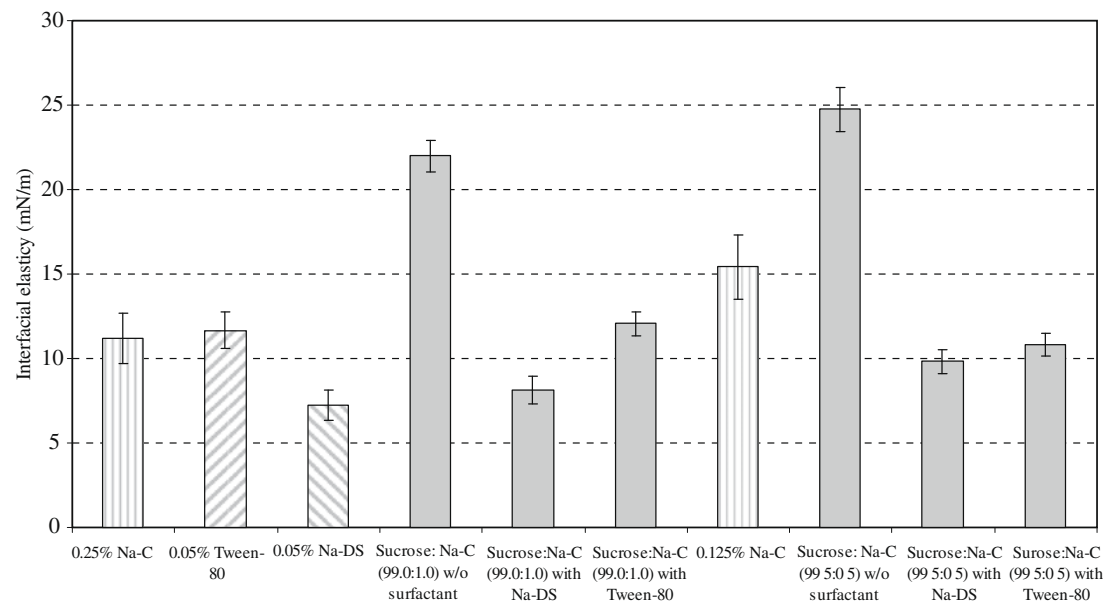

Fig. 5. Surface dilational elasticity of sucrose-Na-C with and without Na-DS and Tween-80 addition. 


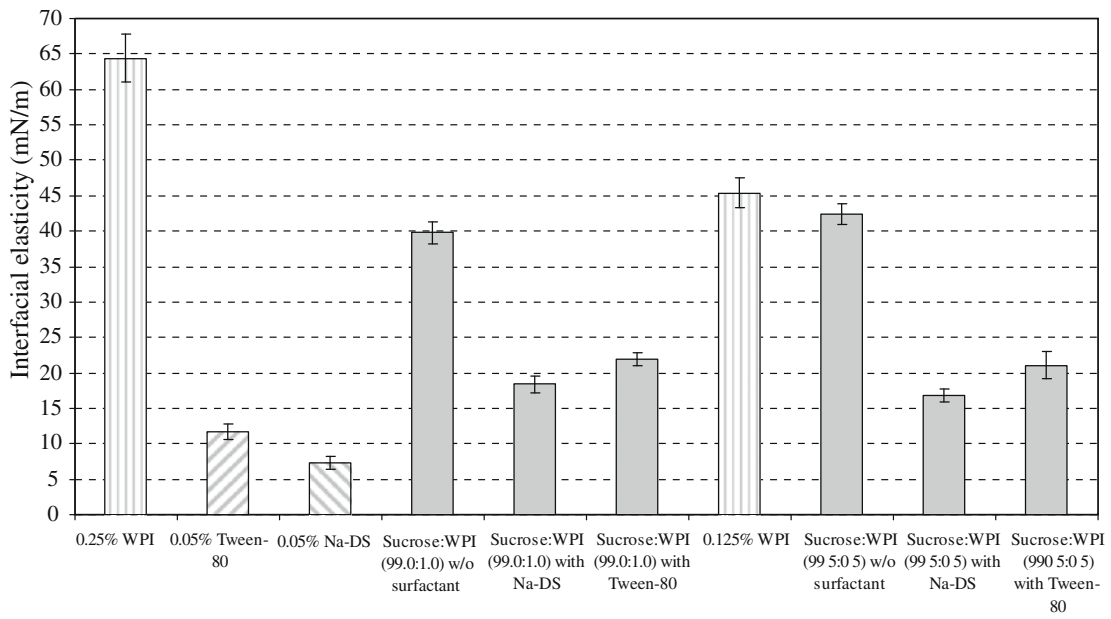

Fig. 6. Surface dilational elasticity of sucrose-WPI with and without Na-DS and Tween-80 addition.

highest dilational elasticity of the order of $67 \pm 4 \mathrm{mN} / \mathrm{m}$ making it the most rigid protein at the air water interface (Mackie et al., 2000). It is not surprising that this property is inherited by WPI as $\beta$ lactoglobulin is a major component of this protein. One of the important features to note here is that the interfacial elasticity of $0.25 \%$ and $0.125 \%$ WPI in sucrose (Fig. 6 ) are very close to each other indicating that in the absence of surfactants the powder recovery will not be different when these two protein concentra tions are used.

\subsubsection{The Orogenic Displacement model of the protein surfactant interaction}

Mackie et al. (1999) and Gunning et al. (2004) explained the protein surfactant interaction at air water interface using the Orogenic Displacement model. According to this model, non ionic surfactants (such as Tween 20 and Tween 80) and ionic surfac tants (such as Na DS) displace the proteins differently. The non io nic surfactants first adsorb and nucleate at defect sites of the protein network. These nucleated domains then grow spatially and start compressing the protein network. At a sufficiently high surface pressure, which is a function of the type of protein, the pro tein network gives way to surfactants and desorbs from the inter face. It was found that $\beta$ casein network is softer and the stress is propagated laterally much easily. Hence, formation of almost uni form and circular or oval surfactant domain takes place at locations where protein is dislodged. In the case of $\beta$ lactoglobulin, since the interfacial elasticity is much stronger, a much stronger network structure is formed where lateral stresses are restricted and hence irregular and fractal type surfactant domains are formed (Mackie et al., 1999; Gunning et al., 2004).

Ionic surfactants such as Na DS are able to nucleate in a much higher number of domains; however, these domains do not grow to a great spatial extent. Hence, the protein is able to resist the dis lodgement. Furthermore, the protein surfactant composite is able to remain intact at much higher surface pressures. For example Mackie et al. (2000) found that in $\beta$ lactoglobulin films, Tween 20 completely displaced protein at a surface pressure of 25 $30 \mathrm{mN} / \mathrm{m}$ where as in the case of $\mathrm{Na}$ DS the displacement of pro tein was not initiated at a surface pressure of $31 \mathrm{mN} / \mathrm{m}$.

We calculated the surface pressure for both the sucrose $\mathrm{Na} C$ and Sucrose WPI solutions with and without LMS. These calcula tions were performed using Eq. (1) below and the data are pre sented in Figs. 3 and 4, respectively.

$\Pi \begin{array}{lll}\Pi & \gamma_{0} & \gamma\end{array}$ where, $\Pi$ is the surface pressure $(\mathrm{mN} / \mathrm{m}), \gamma_{0}$ and $\gamma$ are the surface tension values $(\mathrm{mN} / \mathrm{m})$ of the $25 \%$ sucrose and mixture test solu tions, respectively. Figs. 3 and 4 show that the surface pressure val ues are $3334 \mathrm{mN} / \mathrm{m}$ in the presence of Tween 80 and $4044 \mathrm{mN} / \mathrm{m}$ in the Na DS. From this data, and from the Orogenic Displacement model, it can be seen that the surface pressure required (25 $30 \mathrm{mN} / \mathrm{m}$ ) to dislodge the proteins by Tween 80 has been exceeded. At this level of surface pressure there is no possibility of proteins, even for the more rigid WPI to remain intact on the droplet surface. Hence, it is not surprising that there was zero powder recovery when Tween 80 was added. On the other hand, $31 \mathrm{mN} / \mathrm{m}$ is the minimum of surface pressure for Na DS to start to have some im pact on the structure of the protein films. Probably, this is the start ing point where the protein molecules begin re arranging themselves and start drawing some more molecules from the bulk in response to the increasing surface pressure exerted by Na DS molecules. However, as the electrostatic pressure from Na DS starts to dominate the proteins begin to desorb slowly to the bulk. At the $4044 \mathrm{mN} / \mathrm{m}$ pressure observed in the test solutions, a considerable amount of protein should still remain on the droplet surface. This protein surfactant composite film, when subjected to convective drying appears to be able to form a skin able to offer some degree of resistance to surface stickiness.

\subsubsection{XPS analysis of protein surface coverage}

The elemental composition of carbon, oxygen and nitrogen at the surface of the protein sucrose particles, with our without $\mathrm{Na}$ DS, are presented in Table 4. The elemental compositions of Su crose, Na C, WPI and Na DS are presented as a reference. The the oretical elemental compositions of sucrose, Na DS and Na C along with the extent of error in measurements are presented in Table 5. It can be seen from this table that except for proteins, the error in measurements is within $5 \%$ of the theoretical value. The error in measurement in case of $\mathrm{Na} \mathrm{C}$ is of the order of $10 \%$. As the elemen tal composition data are not available in the case of hydrolyzed WPI and that the molecular formulae was also not readily avail able, there is difficulty in determining the extent of error in mea surements, but they are likely to be consistent with those for $\mathrm{Na}$ C. Furthermore, judging from the measured elemental compo sition of whey protein concentrate (WPC) (Kim et al., 2003), it can be expected that the maximum error in these measurements should be within $10 \%$.

From Table 4 it can be seen that in the absence of Na DS 55\% (expressed as a mass fraction) of the surface of sucrose $\mathrm{Na} C \mathrm{Par}$ ticle is covered by $\mathrm{Na} C$ whereas the mean feed concentration of 
Table 4

Surface composition of spray dried powders of sucrose-Na-C and sucrose-WPI with or without Na-DS.

\begin{tabular}{|c|c|c|c|c|}
\hline Samples & Carbon (\%) & Oxygen (\%) & Nitrogen (\%) & Protein on surface (\%) \\
\hline Sucrose & $53.66 \pm 2.37$ & $46.34 \pm 2.37$ & $0.00 \pm 0.00$ & \\
\hline Sodium Caseinate & $68.28 \pm 0.45$ & $16.93 \pm 0.19$ & $14.53 \pm 0.62$ & \\
\hline Na-DS & $68.74 \pm 1.72$ & $21.26 \pm 0.53$ & $0.00 \pm 0.00$ & \\
\hline Sucrose:Na-C (99.0:1.0) w/o surfactant & $62.98 \pm 0.01$ & $28.52 \pm 0.19$ & $7.93 \pm 0.18$ & $54.56 \pm 2.16$ \\
\hline Sucrose:Na-C (99.0:1.0) with Na-DS & $79.59 \pm 4.90$ & $16.15 \pm 0.81$ & $3.27 \pm 0.30$ & $22.50 \pm 2.31$ \\
\hline Sucrose: Na-C (99.5:0.5) w/o surfactant & $63.82 \pm 0.04$ & $28.84 \pm 0.24$ & $7.34 \pm 0.28$ & $50.51 \pm 3.85$ \\
\hline Sucrose:Na-C (99.5:0.5) with Na-DS & $73.55 \pm 4.50$ & $22.42 \pm 1.12$ & $1.74 \pm 0.09$ & $11.97 \pm 0.80$ \\
\hline WPI & $72.61 \pm 1.01$ & $16.66 \pm 0.71$ & $10.27 \pm 0.50$ & \\
\hline Sucrose:WPI (99.0:1.0) w/o surfactant & $59.19 \pm 2.14$ & $34.98 \pm 1.45$ & $5.69 \pm 0.28$ & $55.40 \pm 4.92$ \\
\hline Sucrose:WPI (99.0:1.0) with Na-DS & $70.14 \pm 3.54$ & $23.91 \pm 1.22$ & $2.41 \pm 0.13$ & $23.46 \pm 1.99$ \\
\hline Sucrose: WPI (99.5:0.5) w/o surfactant & $58.63 \pm 1.02$ & $35.67 \pm 0.38$ & $5.56 \pm 0.27$ & $54.13 \pm 4.96$ \\
\hline Sucrose:WPI (99.5:0.5) with Na-DS & $64.71 \pm 3.31$ & $32.64 \pm 1.63$ & $0.95 \pm 0.06$ & $9.25 \pm 0.83$ \\
\hline
\end{tabular}

this protein was only $1 \%$ on a dry solid basis. As can be seen from Table 2, this level of surface coverage successfully increased the powder recovery from zero to $85 \%$. Similarly $1 \%$ WPI in the bulk feed has resulted in $54 \%$ surface coverage of sucrose WPI particle and that this led to $84 \%$ to $85 \%$ total powder recovery. This extent of surface coverage has become possible due to preferential migra tion of proteins at the air water interface.

When the sucrose:protein solid ratio in the feed was main tained at 99.5:0.5, (nominal protein concentration in feed $=0.125 \%$ ) it can be seen that the protein surface coverage was little different from the one with 99:1. This implied that, where the protein coverage is concerned, the droplet surface has already reached saturation and that no more protein molecules were able to occupy the surface even if the protein concentration in the bulk is increased. The fact that that $0.125 \%$ nominal protein concentration in droplet can attain equilibrium in terms of their surface coverage will have profound implication in using these proteins as 'drying aids'. In fact, as low a nominal feed composition as $0.125 \%$ is possible if one desires to attain maximal protein cov erage at the particle surface.

From Table 2 it has been shown how the LMS lower the powder recovery substantially. For example, the presence of $0.05 \%$ Tween 80 in the feed had such an impact on protein surface coverage that no powder could be produced. This is attributed to two facts. Firstly, the Tween 80 being small in size was able to move to the surface quickly and through Orogenic displacement was able to compel both the Na C and WPI to desorb to the bulk. Secondly, since Tween 80 does not possess the ability to form 'non sticky' glassy skin when it comes in contact with drying air, the surface of the droplet/particle becomes sticky again. This is the reason why no powder was recovered when the nominal feed concentra tion of this LMS was maintained at $0.05 \%$.

The effect of Na DS on powder recovery is not as drastic as that of Tween 80 . Table 4 shows that when $0.05 \%$ Na DS was added to sucrose Na C (99.0:1.0) droplet, the protein surface coverage dropped from $55 \%$ to $23 \%$. This means that the Na DS was able to replace about $59 \%$ of total protein on the droplet surface. This is equally true in case of sucrose WPI droplet as about equal extent of reduction in the surface coverage is observed. At this level of

Table 5

Expected (theoretical) elemental composition of reference materials.

\begin{tabular}{llll}
\hline Samples & Carbon (\%) & Oxygen (\%) & Nitrogen (\%) \\
\hline Sucrose & 52.17 & 47.83 & 0 \\
Error & 2.86 & 3.12 & 0 \\
Sodium Caseinate & 65 & 19 & 16 \\
Error (\%) $_{\text {Polysorbate-80 (Na-DS) }}$ & 5.05 & 10.91 & 9.17 \\
Error & 66.67 & 22.22 & 0 \\
& 3.10 & 4.32 & 0 \\
\hline
\end{tabular}

a Based on molecular formulae (Gaiani et al., 2006). surface coverage (Table 2 ) greater than $50 \%$ total powder recovery can still be achieved. However, when the same amount of Na DS is added to sucrose:protein (99.5:0.5) droplet, the protein surface coverage dipped to between 10 and $12 \%$. At this level of surface coverage (Table 2 ), the recovery dropped to below $40 \%$, which is below our criteria for a successful spray drying operation (Bhan dari et al., 1997).

\section{Conclusion}

A sucrose solution is a typical sugar rich food which cannot be easily converted into a powder form through spray drying due to stickiness. In this study, when $0.125 \%$ protein was added to the solution (sucrose: protein $=99.5: 0.5$ in a $25 \%$ solid feed) the powder recovery was increased to $84 \% 85 \%$. Both the sodium caseinate and hydrolyzed WPI were equally effective to achieve this level of pow der recovery. Increase in protein feed concentration to $0.25 \%$ did not improve the recovery further. When $0.05 \%$ Tween 80 was added to these solutions the observed powder recovery dropped down to zero, indicating that the small Tween 80 molecules sub stantially displaced the proteins from the droplet surface. Addition of $\mathrm{Na}$ DS reduced the powder recovery to below $40 \%$ indicating that this LMS only partially displaced the proteins from the droplet surface. The elemental surface analysis revealed that $58 \% 59 \%$ of the protein was displaced by Na DS in case of droplets containing sucrose:protein in the solid ratio of 99.0:1.0. Similarly, in the case of sucrose:protein $(99.5: 0.5)$ droplets, between $78 \%$ to $82 \%$ of the protein was displaced from the droplet surface. The difference in effectiveness of the Tween 80 and $\mathrm{Na}$ DS in dislodging the protein from the droplet surface can be attributed to their inherently dif ferent surfactant protein interactions which can be explained through the Orogenic Displacement model.

\section{Acknowledgements}

The authors acknowledge the Mr Goh Wei Xiang (Benjamin) for his help in experiments and Australian Research Council (ARC) for financial support for this study.

\section{References}

Adhikari, B., Howes, T., Bhandari, B.R., Truong, V., 2001. Stickiness in foods: a review of mechanisms and test methods. International Journal of Food Properties 4 (1) $1-33$.

Adhikari, B., Howes, T., Bhandari, B.R., Truong, V., 2003. In situ characterization of stickiness of sugar-rich foods using a linear actuator driven stickiness testing device. Journal of Food Engineering 8 (1), 11-22.

Adhikari, B., Howes, T., Shrestha, A.K., Bhandari, B.R., 2007a. Development of stickiness of whey protein isolate and lactose droplets during convective drying. Chemical Engineering and Processing 46 (5), 420-428.

Adhikari, B. Howes, T., Shrestha, A., Bhandari, B.R., 2007b. Effect of surface tension and viscosity on the surface stickiness of carbohydrate and protein solutions. Journal of Food Engineering 79 (4), 1136-1143. 
Adhikari, B., Howes, T., Bhandari, B.R., Langrish, T.A.G., 2009. Effect of addition of proteins on the production of amorphous sucrose powder through spray drying. Journal of Food Engineering. doi:10.1016/j.jfoodeng.2009.01.029.

Bhandari, B.R., Datta, N., Howes, T., 1997a. Problems associated with spray drying of sugar-rich foods. Drying Technology 15 (2), 671-684.

Bhandari, B.R., Datta, N., Crooks, R., Howes, T., Bhandari, B.R., 1997b. A semiempirical approach to optimise the quantity of drying aids required to spray dry sugar-rich foods. Drying Technology 15 (10), 2509-2525.

Dickinson, E., 1999. Adsorbed protein layers at fluid interfaces: interactions, structure and surface rheology. Colloids and Surfaces B-Biointerfaces 15 (2), 161-176.

Faldt, P., Bergenstahl, B., 1996. Spray-dried whey protein/lactose/soybean oil emulsions.2. Redispersability, wettability and particle structure. Food Hydrocolloids. 10 (4), 431-439.

Faldt, P., Bergenstahl, B., Carlsson, G., 1993. The Surface Coverage of Fat on Food Powders Analyzed by ESCA (Electron-Spectroscopy for Chemical-Analysis). Food Structure. 12 (2), 225-234.

Gaiani, C., Ehrhardt, J.J., Scher, J., Hardy, J., Desobry, S., Banon, S., 2006. Surface composition of dairy powders observed by X-ray photoelectron spectroscopy and effects on their rehydration properties. Colloids and Surfaces BBiointerfaces 49 (1), 71-78.

Gunning, P.A., Mackie, A.R., Gunning, A.P., Woodward, N.C., Wilde, P.J., Morris, V.J., 2004. Effect of surfactant type on surfactant-protein interactions at the airwater interface. Biomacromolecules 5 (3), 984-991.

Kim, E.H.J., Chen, X.D., Pearce, D., 2002. Surface characterization of four industrial spray-dried dairy powders in relation to chemical composition, structure and wetting property. Colloids and Surfaces B-Biointerfaces 26 (3), 197-212.

Kim, E.H.J., Chen, X.D., Pearce, D., 2003. On the mechanisms of surface formation and the surface compositions of industrial milk powders. Drying Technology. 21 (2), 265-278.

Langrish, T.A.G., 2007. New engineered particles from spray dryers: research needs in spray drying. Drying Technology 25 (4-6), 971-983.

Maa, Y.F., Hsu, C.C., 1997. Protein denaturation by combined effect of shear and airliquid interface. Biotechnology and Bioengineering 54 (6), 503-512.
Maa, Y.F., Nguyen, P.A.T., Hsu, S.W., 1998. Spray-drying of air-liquid interface sensitive recombinant human growth hormone. Journal of Pharmaceutical Sciences 87 (2), 152-159.

Mackie, A.R., Gunning, A.P., Wilde, P.J., Morris, V.J., 1999. Orogenic displacement of protein from the air/water interface by competitive adsorption. Journal of Colloid Interface Science. 210 (1), 157-166.

Mackie, A.R., Gunning, A.P., Wilde, P.J., Morris, V.J., 2000. Competitive displacement of beta-lactoglobulin from the air/water interface by sodium dodecyl sulfate. Langmuir 16 (21), 8176-8181.

Nijdam, J.J., Langrish, T.A.G., 2006. The effect of surface composition on the functional properties of milk powders. Journal of Food Engineering. 77 (4), 919925.

Pugnaloni, L.A., Dickinson, E., Ettelaie, R., Mackie, A.R., Wilde, P.J., 2004. Competitive adsorption of proteins and low-molecular-weight surfactants: computer simulation and microscopic imaging. Advances in Colloid and Interface Sciences 107 (1), 27-49.

Rouimi, S., Schorsch, C., Valentini, C., Vaslin, S., 2005. Foam stability and interfacial properties of milk protein-surfactant systems. Food Hydrocolloids 19 (3), 467478.

Shrestha, A.K., Howes, T., Adhikari, B.P., Bhandari, B.R., 2007. Effect of protein concentration on the surface composition, water sorption and glass transition temperature of spray-dried skim milk powders. Food Chemistry 104 (4), 14361444 .

Truong, V., Bhandari, B.R., Howes, T., 2005. Optimization of concurrent spray drying process for sugar-rich foods. Part II - Optimization of spray drying process based on glass transition concept. Journal of Food Engineering 71 (1), 66-72.

Van Aken, G.A., 2003. Competitive adsorption of protein and surfactants in highly concentrated emulsions: effect on coalescence mechanisms. Colloids and Surfaces A-Physicochemical and Engineering Aspects 213 (2-3), 209-219.

Weast, R.C., 1988. CRC Handbook of Chemistry and Physics, Student ed. CRC Press, Boca Raton FL.

Williams, A., Prins, A., 1996. Comparison of the dilational behaviour of adsorbed milk proteins at the air-water and oil-water interfaces. Colloids and Surfaces APhysicochemical and Engineering Aspects 114, 267-275. 